\title{
Brain abscesses in a patient with a patent foramen ovale: a case report
}

\author{
Fuad Jan*1, Abdul Moiz Hafiz², Saurabh Gupta1, John Meidl³ and \\ Suhail Allaqaband ${ }^{1}$
}

\begin{abstract}
Address: ${ }^{1}$ Department of Medicine, Division of Cardiovascular Disease, University of Wisconsin School of Medicine and Public Health, Milwaukee Clinical Campus, North 12th Street, Milwaukee, Wisconsin, 53233, USA, ${ }^{2}$ Department of Medicine, Winthrop-University Hospital, Mineola, New York, USA and ${ }^{3}$ Department of Medicine, Division of Infectious Diseases, University of Wisconsin School of Medicine and Public Health, Milwaukee Clinical Campus, North 12th Street, Milwaukee, Wisconsin, 53233, USA

Email: Fuad Jan* - fuad.jan@aurora.org; Abdul Moiz Hafiz - hafizabdulmoiz@hotmail.com; Saurabh Gupta - saurabh0153@gmail.com; John Meidl - jmeidl1@wi.rr.com; Suhail Allaqaband - sallaqaband@hrtcare.com

* Corresponding author
\end{abstract}

Published: 25 November 2009

Journal of Medical Case Reports 2009, 3:9299 doi:10.1 186/1752-1947-3-9299
Received: 27 October 2009

Accepted: 25 November 2009

This article is available from: http://www.jmedicalcasereports.com/content/3/l/9299

(C) 2009 Jan et al; licensee BioMed Central Ltd.

This is an Open Access article distributed under the terms of the Creative Commons Attribution License (http://creativecommons.org/licenses/by/2.0), which permits unrestricted use, distribution, and reproduction in any medium, provided the original work is properly cited.

\begin{abstract}
Introduction: Brain abscesses arising from right-to-left cardiac shunting are very rare in adults.

Case presentation: We describe the case of a 47-year-old non-hispanic white male with periodontal disease who developed several brain abscesses caused by Streptococcus intermedius. A comprehensive workup revealed a patent foramen ovale with oral flora as the only plausible explanation for the brain abscesses.
\end{abstract}

Conclusion: Based on this case and the relevant literature, we suggest an association between a silent patent foramen ovale, paradoxical microbial dissemination to the brain, and the development of brain abscesses.

\section{Introduction}

Brain abscesses develop as a result of the contiguous spread of infection from the sinuses, otic or odontogenic primary sources, or as a result of hematogenous spread from distant locations. In $10 \%$ to $60 \%$ of patients with brain abscess, no underlying source of infection is found. Unlike children with congenital heart disease, minor right-to-left intracardiac shunting due to a patent foramen ovale (PFO) is not recognized as a cause of brain abscess in adults.

\section{Case presentation}

A 47-year-old non-hispanic white male from United States, with a history of alcohol abuse presented to the emergency department of our hospital with nausea, vom- iting, fever and severe headache of a two-week duration. On examination, he was found to have an altered sensorium, periodontal disease and low-grade fever. Laboratory evaluation was unremarkable except for a white cell count of 13,400 cells $/ \mu \mathrm{l}$ (normal range 4,000-11,000 cells $/ \mu \mathrm{l}$ ). Magnetic resonance imaging (MRI) of the brain (Figure 1A) showed 15 to 20 ring enhancing lesions in both the cerebral hemispheres and the midbrain.

Craniotomy and biopsy revealed multiple abscesses positive for Streptococcus intermedius. A search for the primary source of infection led to an extensive workup that included tests for neurocysticercosis, human immunodeficiency virus, tuberculosis, rheumatology panel, and computed tomography of the chest, abdomen and pelvis, 


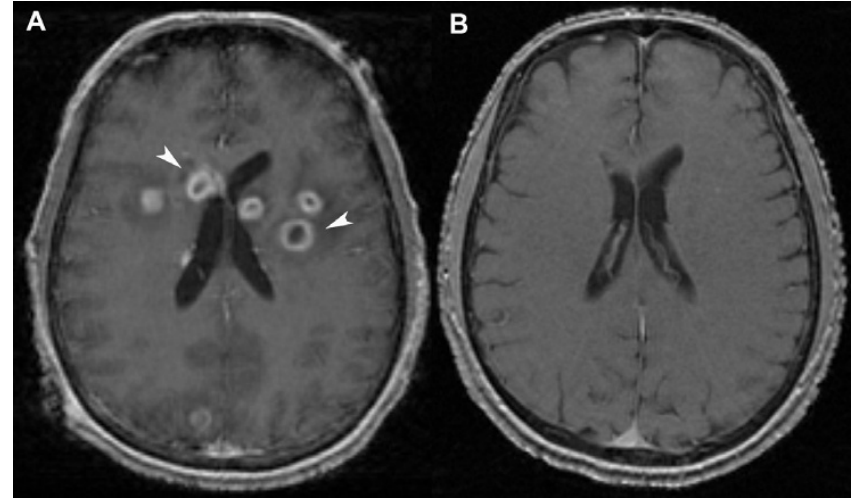

Figure I

Magnetic resonance imaging of the brain. (A) TIweighted images at the patient's presentation, post-contrast showing multiple ring enhancing lesions in the brain (white arrow heads). (B) TI-weighted images eight months after treatment showing a resolution of the brain abscesses.

all of which returned normal results. A transesophageal echocardiogram to look for vegetations (Figure 2A), revealed a moderate-sized $\mathrm{PFO}$ with a bidirectional shunt, which was confirmed with the use of agitated saline bubble contrast echocardiography (Figure 2B).

Our patient's PFO was believed to be the pathway for his cerebral abscesses. He was started on a prolonged course of antibiotics and discharged from the hospital after two weeks. The follow-up MRI scans improved gradually (Figure $1 \mathrm{~B}$ ) and he experienced a complete clinical recovery. Eight months later he underwent a closure of the PFO with a GORE HELEX device.

\section{Discussion}

PFO has a prevalence of $25 \%$ in the general population [1], and it has been proposed that oropharyngeal bacteria may access the brain vascular system through a PFO [2]. Although congenital intracardiac shunts are known to be a path for pediatric brain abscesses, and extracardiac shunts such as pulmonary arteriovenous malformation are recognized to be pathways in adults, clinically silent intracardiac shunting due to PFO is not a recognized source of septic brain emboli in adults. The spectrum of organisms found in brain abscesses reflects the range of underlying primary sources of infection. Although in 10\% to $60 \%$ of patients with brain abscess no underlying source of infection is found, a PFO may precipitate the development of brain abscess in these cases [3].

Our patient's brain abscesses had no precipitating factors other than a PFO, which was detected by an agitated saline bubble contrast echocardiography. The association of the brain abscess with dental sepsis is suggested by the

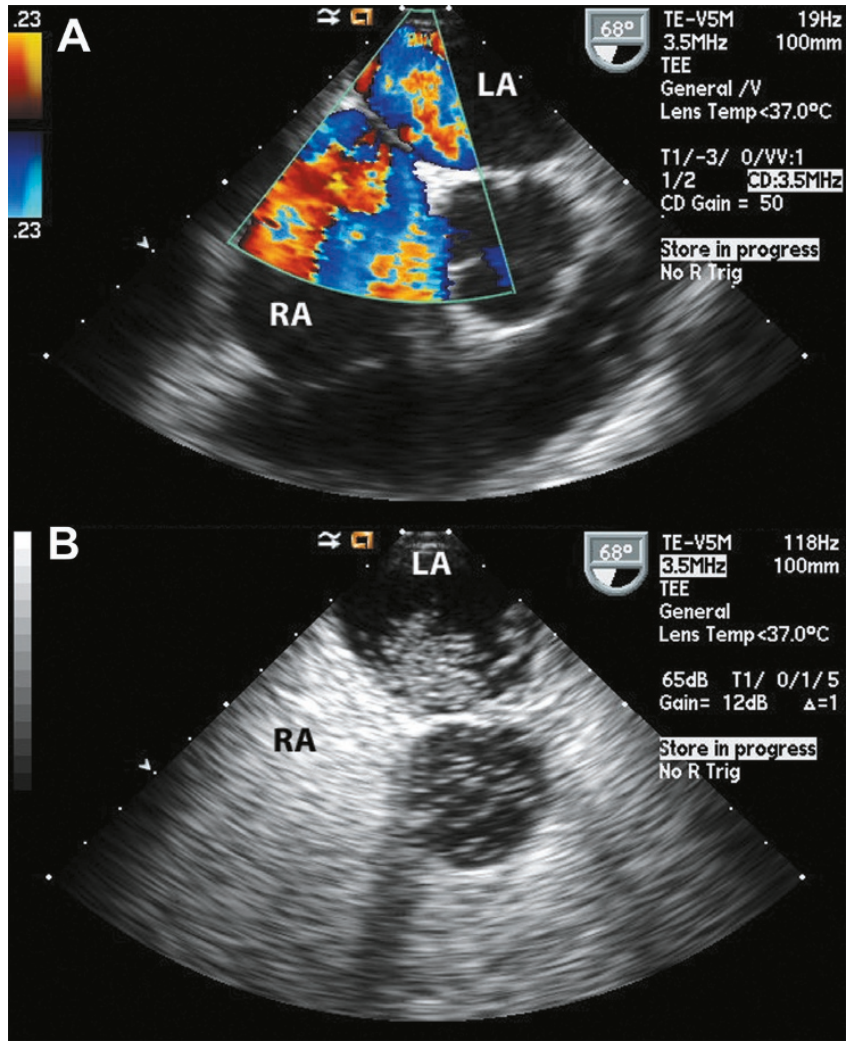

Figure 2

Transesophageal echocardiography during the patient's initial hospitalization. (A) A bidirectional interatrial shunt seen through the patent foramen ovale. RA, right atrium; LA, left atrium. (B) Injection of agitated saline through an upper extremity peripheral vein showing the appearance of bubbles crossing from the right to the left atrium. RA, right atrium; LA, left atrium.

isolation of oral Streptococcus milleri group of organisms (Streptococcus intermedius in our case). Isolated cases in the literature have suggested that all patients in whom an oropharyngeal pathogen is isolated from brain abscesses must be screened for a PFO by transesophageal echocardiogram [4]. Management options include medical therapy with antiplatelet agents or anticoagulation (for stroke prevention) and surgical or percutaneous closure of the defect.

\section{Conclusion}

A minor PFO is not recognized as a source of brain abscesses in adult patients. However, it may become a source of brain abscesses in rare cases. This case highlights a possible link between a silent PFO and the development of brain abscesses, particularly with oral flora. To the best of our knowledge, there were very few instances in the past where such a possibility was considered. As such, this possibility should be kept in mind when evaluating 
patients with brain abscesses in whom the underlying cause seems unclear.

\section{Consent}

Written informed consent could not be obtained because the patient was lost to follow-up. Every effort has been made to conceal the identity of the patient and we believe that the patient and their family would not object to publication of this case report.

\section{Competing interests}

The authors declare that they have no competing interests.

\section{Authors' contributions}

FJ, JM and SA cared for the patient while he was admitted in the hospital. They later reviewed, edited and approved the final draft of the manuscript. AMH and SG reviewed the charts and the literature, and also drafted the manuscript.

\section{References}

I. Lechat P, Mas JL, Lescault G, Loron P, Theard M, Klimczac M, Drobinski G, Thomas D, Grosgogeat Y: Prevalence of patent foramen ovale in patients with a stroke. N Engl J Med 1988, 318: I I48-III52.

2. Kundra SN: Patent foramen ovale as possible risk factor for cryptogenic brain abscess: report of two cases. Neurosurg 2002, 50:674-675.

3. Kawamata T, Takeshita M, Ishizuka N, Hori T: Patent foramen ovale as a possible risk factor for cryptogenic brain abscess: report of two cases. Neurosurg 200I, 49:204-207.

4. Khouzam RN, El-Dokla AM, Menkes DL: Undiagnosed patent foramen ovale presenting as a cryptogenic brain abscess: case report and review of the literature. Heart \& Lung 2006, 35: $108-11$ II.
Publish with Bio Med Central and every scientist can read your work free of charge

"BioMed Central will be the most significant development for disseminating the results of biomedical research in our lifetime. "

Sir Paul Nurse, Cancer Research UK

Your research papers will be:

- available free of charge to the entire biomedical community

- peer reviewed and published immediately upon acceptance

- cited in PubMed and archived on PubMed Central

- yours - you keep the copyright

Submit your manuscript here:

http://www.biomedcentral.com/info/publishing_adv.asp 